\title{
Propagule size and sex ratio influence colonisation dynamics after experimental introduction of a non-native lizard
}

\author{
Amélie Fargevieille ${ }^{1}$, Aaron Reedy ${ }^{1}$, Ariel Kahrl ${ }^{2}$, Timothy Mitchell ${ }^{1}$, Andrew Durso ${ }^{3}$, \\ David Delaney ${ }^{4}$, Phillip Pearson ${ }^{1}$, Robert Cox $^{2}$, and Daniel Warner ${ }^{1}$
}

\author{
${ }^{1}$ Auburn University \\ ${ }^{2}$ University of Virginia \\ ${ }^{3}$ Florida Gulf Coast University \\ ${ }^{4}$ Iowa State University
}

August 20, 2020

\begin{abstract}
The composition of founding populations plays an important role in colonisation dynamics and likely influences population growth during early stages of biological invasion. We tested the effects of founding population size (propagule size) and sex ratio on offspring production and annual population growth following experimental introductions of a non-native lizard species (Anolis sagrei). We manipulated propagule composition on nine small islands, then examined offspring production, population growth rate and survival rate of founders and their descendants encompassing four generations. By the third reproductive season, per capita offspring production was higher on islands seeded with a larger number of individuals. Population growth during the first year was negative on islands with male-biased propagules, but positive over the subsequent year, likely due to shifts in sex ratio. This study demonstrates that propagule size drives colonization dynamics in this species while male biases in propagule sex ratio may temporarily slow the invasion process.
\end{abstract}

\section{Hosted file}

MS_ColonisationDynamics_Asagrei.pdf available at https://authorea.com/users/352513/articles/ 476731-propagule-size-and-sex-ratio-influence-colonisation-dynamics-after-experimentalintroduction-of-a-non-native-lizard 